\title{
Peptide Ozonolysis: Product Structures and Relative Reactivities for Oxidation of Tyrosine and Histidine Residues
}

\author{
Julie A. Lloyd, Jeffrey M. Spraggins, and Murray V. Johnston \\ Department of Chemistry and Biochemistry, University of Delaware, Newark, Delaware, USA \\ Julia Laskin \\ Fundamental Science Directorate, Pacific Northwest Laboratories, Richland, Washington, USA
}

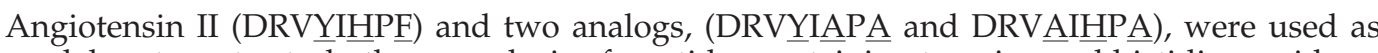
model systems to study the ozonolysis of peptides containing tyrosine and histidine residues. The ESI mass spectrum of angiotensin II following exposure to ozone showed the formation of adducts containing one, three, and four oxygen atoms. CID and SID spectra of these adducts were consistent with formation of $\mathrm{Tyr}+\mathrm{O}$ and $\mathrm{His}+3 \mathrm{O}$ as expected from previous work with amino acids. However, several fragment ions observed in the CID and SID spectra suggested formation of a rather unexpected adduct, $\mathrm{Tyr}+3 \mathrm{O}$, and a small amount of the Phe $+\mathrm{O}$ adduct. These findings were confirmed by examining two angiotensin analogs. Exposure of DRVYIAPA to ozone resulted in the addition of either one or three oxygen atoms on Tyr, while DRVAI I $\underline{\text { PA }}$ showed only the addition of three oxygen atoms-all on His. Other noteworthy minor oxidation products were observed from these analogs including Tyr $+34 \mathrm{Da}$, His +5 $\mathrm{Da}$, His $+34 \mathrm{Da}$, and His $+82 \mathrm{Da}$. The reaction rates of the peptides with ozone were found to be similar: second-order rate coefficients are $274 \pm 3,379 \pm 6$, and $439 \pm 34 \mathrm{M}^{-1} \mathrm{~s}^{-1}$ for DRVYIAPA, DRVAIHPA, and angiotensin II, respectively. The relative rates indicate (1) an isolated His residue has a slightly greater ozone reactivity than an isolated Tyr residue, and (2) the reaction rates of isolated residues are not additive when both residues are present in the same molecule. (J Am Soc Mass Spectrom 2006, 17, 1289-1298) (c) 2006 American Society for Mass Spectrometry
\end{abstract}

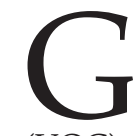
round level ozone, one of the most toxic pollutants, is formed by the reaction of nitrogen oxides (NOx) and volatile organic compounds (VOC) in the presence of sunlight. Emissions from motor vehicles and industrial processes are the major sources of NOx and VOC. The national ambient air quality standard (NAAQS) for ozone is currently 0.08 ppm averaged over an $8 \mathrm{~h}$ period. This level is often exceeded in the United States and elsewhere. Human exposure to high levels of ozone has been shown to cause adverse human health effects such as decreased respiratory function, aggravated asthmatic symptoms [1, 2], and dry eye syndrome [3]. Deleterious effects on animal lung function and agricultural crops and forests have also been observed [4-6].

Because of potential severe health effects, many studies have focused on the reaction of ozone with key biomolecular targets in the respiratory tract, including lipids [7, 8], proteins [7-11], and antioxidants in the

Published online July 3, 2006

Address reprint requests to Dr. M. V. Johnston, Department of Chemistry and Biochemistry, University of Delaware, Newark, DE 19716, USA. E-mail: mvj@udel.edu respiratory tract lining fluid (RTLF) such as uric acid and ascorbic acid $[12,13]$. Inactivation and/or denaturation upon exposure to ozone has been shown for lysozyme [14, 15], glutamine synthetase [16], glyceraldehyde-3-phosphate dehydrogenase (G3PDH) [17], and acetylcholine esterase (AChE) [18]. Biomolecular targets also exist in atmosphere, either within viable cells (bacteria, fungal spores, etc.) or nonviable biological debris (leaf fragments, biomass burning aerosol, etc.) [19]. The roles these materials play in processes such as cloud formation [20], ice nucleation [21], and adverse health effects [22] are not well understood, and are complicated by reaction with oxidants such as ozone, which can modify their physical, chemical, and biological properties.

Spectrophotometric studies have shown that the amino acids Met, Trp, Tyr, Cys, His, and Phe are most susceptible to oxidation by ozone in aqueous solutions [23-26]. The reaction rates depend on solution conditions such as $\mathrm{pH}$, as well as the precise method of ozonolysis and detection employed [12, 23, 24]. These studies have been performed mainly with UV absorbance, which permits characterization of carbonyls formed by side-chain oxidation and fluorescence- 
quenching that permits characterization of Trp oxidation. Recently, the ozonolysis products of free amino acids and several di- and tripeptides have been characterized by ESI-MS/MS [27]. Although product structures have been proposed in these studies, the mechanisms of these reactions are not completely understood. Also, the potential of other oxidizing agents (i.e., $\mathrm{H}_{2} \mathrm{O}_{2}$, hydroxyl radicals, or ${ }^{1} \mathrm{O}_{2}$ ) resulting from ozonolysis of biomolecules have not been discussed in detail.

In the work presented here, the ozonolysis of Tyr and His are studied using angiotensin II (DRV $\underline{Y} \underline{\mathrm{H}} \underline{\mathrm{P}} \underline{\mathrm{F}})$ and two related analogs, (DRVYIAPA and DRV $\underline{A} \underline{H} \underline{H}$ ), as model systems. The analogs provide the opportunity to study Tyr and His oxidation individually within a more complex molecule compared to free amino acid studies. New oxidation products of Tyr are observed, and the rates of reaction of these peptides are also determined.

\section{Methods}

Angiotensin II (DRV $\underline{\text { I }} \underline{\mathrm{H}} \mathrm{P} \underline{\mathrm{F}})$, bradykinin, and adrenocorticotropic hormone (ACTH) fragment 18-39 were obtained from Sigma-Aldrich (St. Louis, MO) and two analogs (DRVYIAPA and DRVAI $\underline{A P} \underline{A}$ ) from AnaSpec, Inc. (San Jose, CA) HPLC grade methanol and acetonitrile were obtained from Fisher. Aqueous solutions of angiotensin II and its analogs were prepared in deionized water (Millipore, Bedford, MA) at a concentration of $0.15 \mathrm{mg} / \mathrm{mL}$. Bradykinin and ACTH fragment 18-39 were prepared at concentrations of 0.30 and $0.10 \mathrm{mg} / \mathrm{ml}$, respectively. The reaction was performed by flowing ozone over the stirred peptide solutions for up to $21 \mathrm{~min}$. Aliquots were removed at different time periods and immediately cleaned with a C18 ZipTip (Millipore) to remove potential oxidizing agents. Ozone was produced by an ozone generator model PZ5 (Prozone International, Inc., Huntsville, AL) with a flow rate of $\sim 1.2$ $\mathrm{L} / \mathrm{min}$. The gas-phase concentration of ozone introduced to the reaction system was measured with a model $49 \mathrm{C} \mathrm{O}_{3}$ Analyzer (Thermo Electron, Franklin, MA). Solution phase concentrations were then determined from the Henry's law constant for ozone [28].

MS and MSMS spectra of electrosprayed ions were obtained using an LCQ Advantage ion trap mass spectrometer (ThermoFinnigan, San Jose, CA). Nitrogen was used as the nebulizer gas with an applied positive voltage of $4.5 \mathrm{kV}$ to the electrospray needle. Samples were mixed with methanol to a $1: 1 \mathrm{vol} / \mathrm{vol}$ ratio and then manually injected into a $20 \mu \mathrm{L}$ stainless steel injection loop. A $100 \%$ acetonitrile carrier solution delivered the sample to the electrospray interface at a flow rate of $40 \mu \mathrm{L} / \mathrm{min}$. Mass spectra were acquired between 150 and $2000 \mathrm{~m} / \mathrm{z}$ with a 50-ms activation time. For MSMS, the isolation width for selected ions was set at 3 $\mathrm{m} / \mathrm{z}( \pm 1.5 \mathrm{~m} / \mathrm{z})$, and the \% relative collision energy was set at $35 \%$ with a $200-\mathrm{ms}$ activation time. Default values of 0.25 and $30 \mathrm{~ms}$ were used for activation $\mathrm{Q}$ and time, respectively. All spectra were collected in full scan mode and analyzed using Xcalibur software (ThermoFinnigan).

Surface-induced dissociation (SID) of angiotensin II was studied using a custom built 6-T Fourier transform ion cyclotron resonance (FT-ICR) mass spectrometer (Pacific Northwest National Laboratory, Richland, WA) described elsewhere [29]. In these experiments, ions were produced in a high-transmission electrospray source consisting of an ion funnel interface followed by three quadrupoles used for collisional focusing, mass selection, and external accumulation, respectively. After accumulation, the ions were extracted from the third quadrupole and transferred into the ICR cell, where they collided with the surface positioned at the rear trapping plate of the cell. The resulting scattered ions were trapped, excited by a broadband chirp, and detected. The SID surface used in this study is a $2 \mu \mathrm{m}$ thick film of carbon vapor deposited diamond on titanium disk prepared by P1 Diamond Inc. (Santa Clara, CA).

\section{Results and Discussion}

Ozone reactions in the presence of water may lead to the formation of additional oxidizing agents such as hydrogen peroxide, hydroxyl radicals, and singlet oxygen. The presence of oxidizing agents during electrospray ionization can lead to the formation of electrochemically generated oxygen adducts [30]. Formation of oxygen adducts can also occur in electrospray by simply increasing the needle voltage [31]. Therefore, control experiments were designed to identify the formation of products based on intermediate oxidizing agents and electrochemical generation in the ESI source.

Potential oxidizing agents were introduced to the stirred peptide solutions to understand whether or not formation of products occurred. First, oxygen was eliminated as a potential oxidizing agent. Dry, filtered air was flowed over the stirred peptide solutions and directly injected into the ESI source. Spectra of each peptide control solution verified that no oxidation products were produced in the absence of ozone. Second, $\mathrm{H}_{2} \mathrm{O}_{2}$ was added in excess to the peptide solutions before MS analysis. The mass spectra showed addition of up to four oxygen atoms in small abundance, presumably due to the electrochemical generation of reactive oxygen species during electrospray ionization. Sample cleanup with a C18 ZipTip (Millipore) just before injection into the ESI source eliminated formation of these oxygen adducts [32]. It was concluded that any $\mathrm{H}_{2} \mathrm{O}_{2}$ formed during the ozonolysis process will be removed by sample cleanup and will not cause additional oxidation in the ESI source.

Hydroxyl radicals resulting from the decomposition of ozone in solution were not experimentally removed from the reaction system. However, because the selectivity of ozone is high for specific substrates (i.e., Met, Trp, Tyr, His, etc), and this selectivity was maintained in the experiments described above, it is concluded that 
the observed reaction products are primarily the result of ozone oxidation and not from the less selective oxidation by hydroxyl radicals [33].

Singlet oxygen $\left({ }^{1} \mathrm{O}_{2}\right)$ was also considered to be a potential oxidizing agent in these experiments. Unfortunately, the contribution of ${ }^{1} \mathrm{O}_{2}$ is difficult to eliminate in ozone reactions because most ${ }^{1} \mathrm{O}_{2}$ quenchers will rapidly react with ozone. Earlier work by Kanofsky et al. $[13,34]$ showed singlet oxygen yields of $0.12 \pm 0.02$ and $0.09 \pm 0.02\left(\mathrm{~mol}^{1} \mathrm{O}_{2} / \mathrm{mol} \mathrm{O}_{3}\right.$ reacted $)$ for tyrosine and histidine, respectively, at gas-liquid interfaces of ozone-biomolecule reactions. Based on these low yields and the substrate oxidation selectivity observed in the experiments, the generation and eventual reaction of singlet oxygen with peptide is expected to be minimal. It cannot be discounted, however, that hydroxyl radicals and singlet oxygen can contribute to the formation of minor oxidation products observed in this study.

\section{ESI-MS}

Figure 1a shows the ESI mass spectrum of angiotensin II (DRVYIIHPF) after exposure to ozone. In addition to the unreacted parent peak at $1046.6 \mathrm{~m} / \mathrm{z}$, singly charged oxidation products appear at 1062.5, 1094.5, and 1110.5 $\mathrm{m} / \mathrm{z}$, which correspond to the addition of one, three, and four oxygen atoms, respectively. Table 1 gives accurate mass measurements that confirm the expected elemental composition of the products. Previous work showed that ozonolysis of free amino acids results in the addition of one oxygen atom to Tyr and three oxygen atoms to His [27]. Other ions in the mass spectrum suggest the addition of five and six oxygen atoms (1126.4 and $1142.5 \mathrm{~m} / \mathrm{z}$, respectively), which most likely result from continuing the ozone reaction. Unfortunately, the relative abundances of these ions were too small to allow further characterization. No significant ion current is observed at $\mathrm{m} / \mathrm{z}$ values corresponding to M-30 (decarboxylation) or M-43 (deguanidination), which might be expected from hydroxyl radical mediated oxidation.

To study Tyr and His oxidation individually, three residues were modified in the angiotensin II peptide. His and Phe were replaced by Ala in one analog leaving Tyr as the only reactive amino acid (DRVYIAPA), and Tyr and Phe were replaced by Ala in the other analog leaving $\mathrm{His}$ as the only reactive amino acid (DRV $\underline{\text { AIHP}} \underline{\mathrm{A}}$ ). Although oxygen addition products were not anticipated for Phe in angiotensin II, earlier work suggested that trace amounts of Phe $+\mathrm{O}$ and Phe $+2 \mathrm{O}$ may be formed by ozonolysis and are detectable by mass spectrometry [27]. Therefore, experiments were also conducted on bradykinin (RPPGFSR) under the same reaction conditions to study the possible reactivity of Phe. The ESI mass spectrum of bradykinin after exposure to ozone did not show any oxidation products, suggesting that Phe undergoes little if any oxidation under the conditions used in this study.

Figure $1 \mathrm{~b}$ shows the ESI mass spectrum of A6, A8-angiotensin II, DRVYIAPPA, after exposure to ozone.
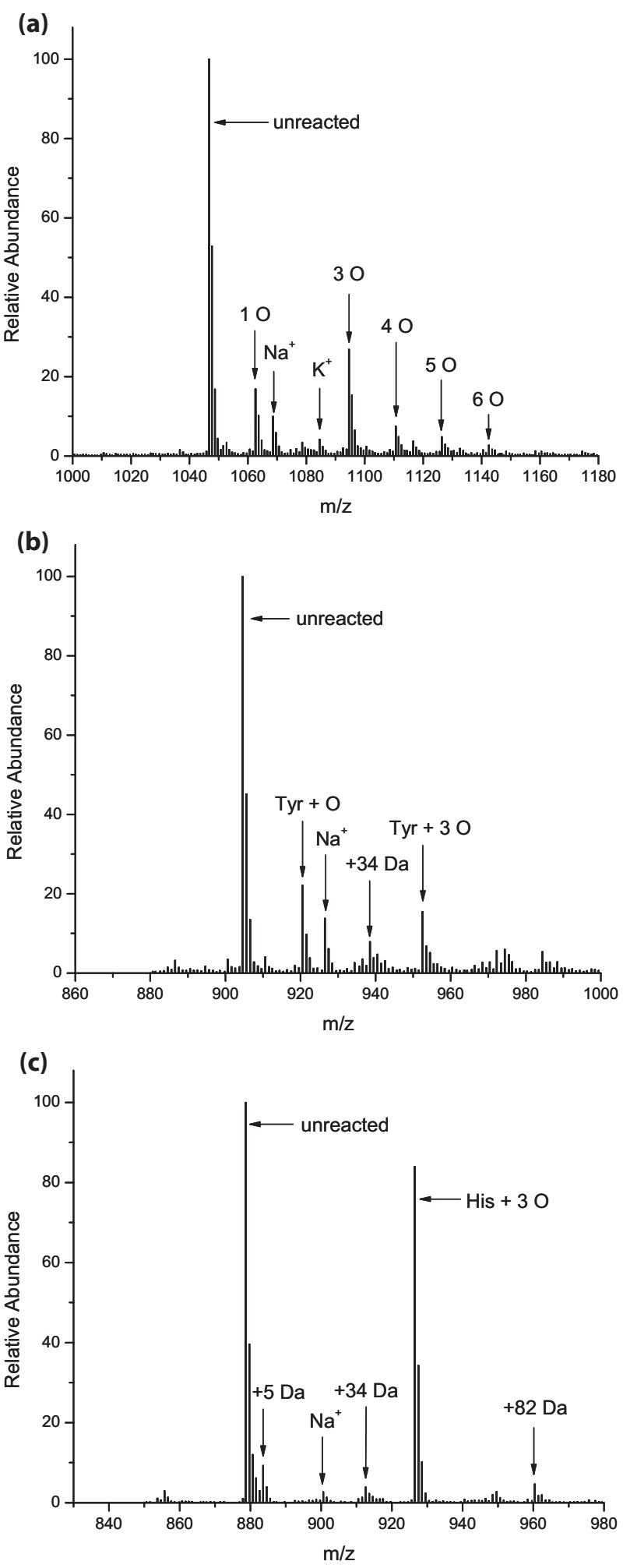

Figure 1. ESI mass spectrum of (a) angiotensin II, (b) DRV $\underline{Y-}$ IAPA, and (c) DRV $\underline{A} \underline{H} \underline{H} \underline{A}$ after exposure to ozone.

In addition to the unreacted molecule appearing at $904.6 \mathrm{~m} / \mathrm{z}$, oxidation products are observed at 920.5 and $952.5 \mathrm{~m} / \mathrm{z}$, which correspond to the addition of one and three oxygen atoms, respectively. While the addition of one oxygen atom on Tyr was expected based on previ- 
Table 1. Accurate mass measurements obtained from FT-ICR mass spectra for angiotensin II and ACTH fragment 18-39

\begin{tabular}{lccccrrr}
\hline & \multicolumn{3}{c}{ Angiotensin II } & & \multicolumn{2}{c}{ ACTH fragment 18-39 } \\
\cline { 2 - 4 } Adducts & Exp. & Meas. & $\Delta$ (Exp.-meas.) & & Exp. & Meas. & $\Delta$ (Exp.-meas.) \\
\hline \hline Unreacted & 1046.5423 & 1046.5457 & -0.0034 & 1233.1034 & 1233.1085 & -0.0051 \\
+ O & 1062.5372 & 1062.5397 & -0.0025 & 1241.1008 & 1241.0961 & 0.0047 \\
+ 3 O & 1094.5270 & 1094.5300 & -0.0027 & 1257.0957 & 1257.0978 & -0.0021 \\
+ 4 O & 1110.5220 & 1110.5223 & -0.0003 & & \\
\hline
\end{tabular}

ous work [27], the addition of three oxygen atoms is rather surprising and has not been previously reported. This observation can be rationalized assuming formation of a ring-opened degradation product discussed in detail below. Another oxidation product of DRVYIAPA appears in the mass spectrum at $938.5 \mathrm{~m} / \mathrm{z}$ corresponding to the addition of $34 \mathrm{Da}$ to the original peptide. Ions with $\mathrm{m} / \mathrm{z}$ greater than the $3 \mathrm{O}$ adduct at $952.5 \mathrm{~m} / \mathrm{z}$ most likely result from the continuing attack of ozone on the oxidized products and/or oxidation of nonspecific targets on the peptide.

Further evidence for formation of a Tyr $+3 \mathrm{O}$ adduct is found in the ESI mass spectrum of ACTH fragment 18-39 (RPVKVYPNGAEDESAEAFPLEF), which after exposure to ozone shows a doubly charged ion at 1233.3 $\mathrm{m} / \mathrm{z}$ from the unreacted molecule, a doubly charged ion at $1241.3 \mathrm{~m} / z$ corresponding to the addition of one oxygen atom, and a doubly charged ion at $1257.7 \mathrm{~m} / \mathrm{z}$ correlating to the addition of three oxygen atoms (data not shown). Accurate mass measurements obtained using FT-ICR mass spectrometry confirmed the expected elemental compositions (Table 1). Although the mass and peptide length of the ACTH fragment 18-39 was double compared to angiotensin II, both peptides contained similar potential reactive amino acids (i.e., Tyr and Phe). Since the Phe residue is not expected to react significantly with ozone on this time scale, the ACTH mass spectrum is consistent with formation of an oxidation product corresponding to Tyr $+3 \mathrm{O}$. Also, reaction of the Phe residue with other oxidizing agents such as a hydroxyl radical would result in the addition of only one oxygen atom not three.

Figure 1c shows the ESI mass spectrum of A4, A8-angiotensin II, DRVAIHPA, after exposure to ozone. Because His is the only residue that reacts with ozone, the oxidation product at $926.5 \mathrm{~m} / z$ is assigned to His + $3 \mathrm{O}$ as previously reported [27]. Minor oxidation products of DRV $\underline{\text { AIHPA }} \underline{\mathrm{A}}$ appear at $883.6,912.6$ and $960.4 \mathrm{~m} / \mathrm{z}$ corresponding to the addition of 5,34 , and $82 \mathrm{Da}$, respectively, to the peptide. Assuming oxidation only occurs on the His residue, the His $+34 \mathrm{Da}$ and His +82 $\mathrm{Da}$ adducts have not been previously reported. However, the $+5 \mathrm{Da}$ adduct was recently identified by mass spectrometry to be formyl-asparagine as a product of radiolytically oxidized peptides (e.g., $\mathrm{M}+2 \mathrm{O}-\mathrm{CNH}$ ) [35]. Earlier studies identified the $+5 \mathrm{Da}$ adduct, where a model compound, N-benzoylhistidine, was reacted in $\mathrm{a} \mathrm{Cu}^{2+} / \mathrm{H}_{2} \mathrm{O}_{2}$ system [36] and a $\mathrm{Cu}^{2+} /$ ascorbate system [37], where the main oxidizing agent was a hydroxyl radical. Therefore, possibly the minor $+5 \mathrm{Da}$ adduct was formed by a radical-based oxidation. Unfortunately, further MSMS characterization of the DRV $\underline{A} \underline{H} \underline{A}$ minor oxidation products was not possible due to low signal intensities.

\section{ESI-MSMS-CID and SID}

MSMS experiments were performed on the major oxidation products of angiotensin II and the two analogs to determine the location of oxygen addition. CID spectra of all three peptides are shown in Figures 2, 3, and 4,
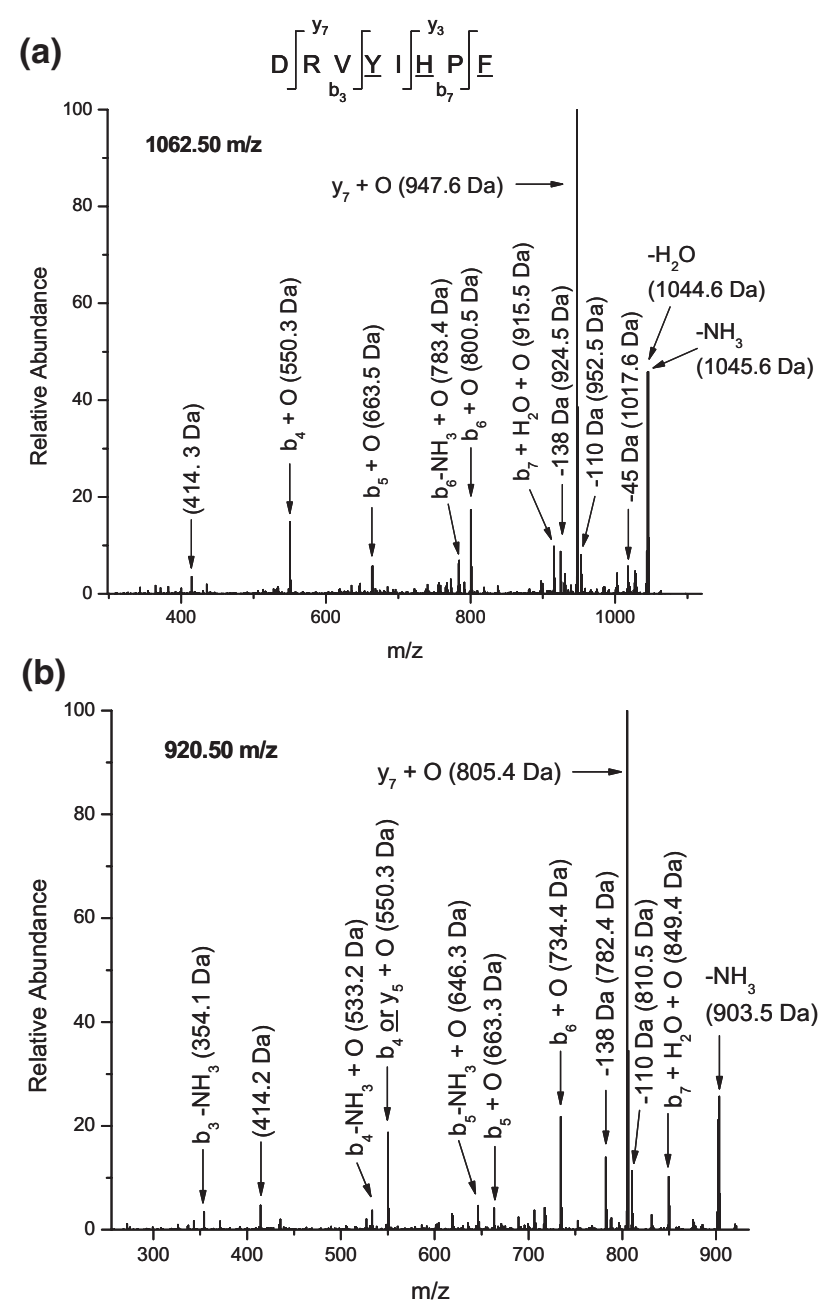

Figure 2. CID spectra of the $+\mathrm{O}$ adducts in (a) angiotensin II at $1062.5 \mathrm{~m} / \mathrm{z}$ and (b) DRVYIAPA at $920.2 \mathrm{~m} / \mathrm{z}$. 


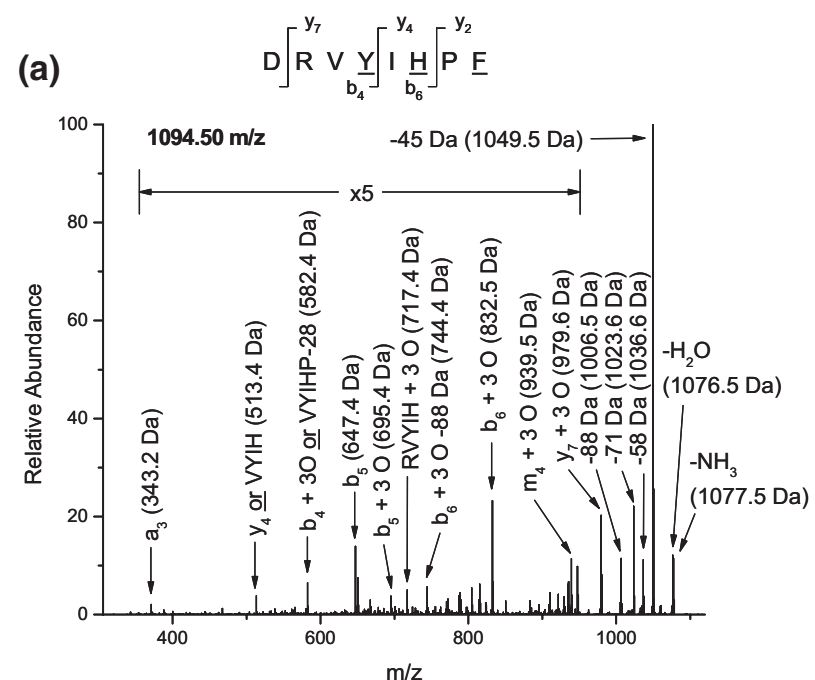

(b)

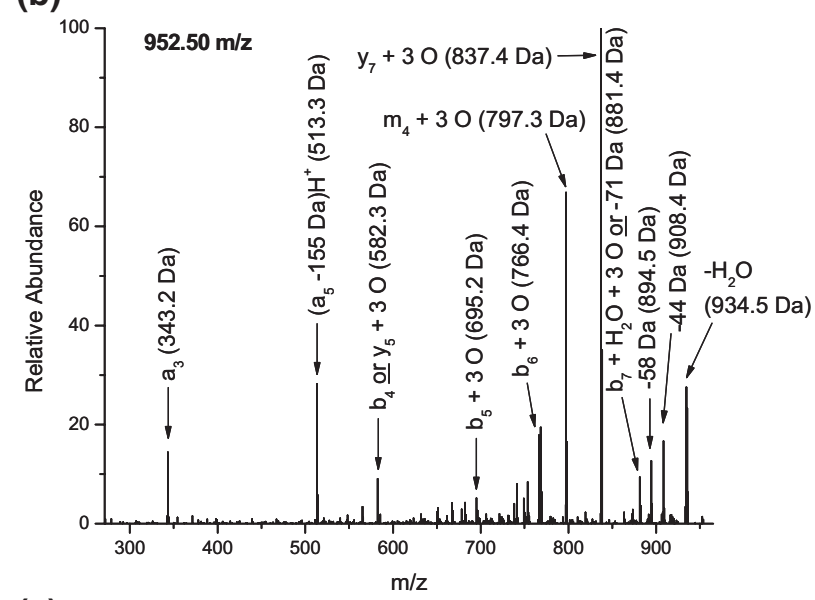

(c)

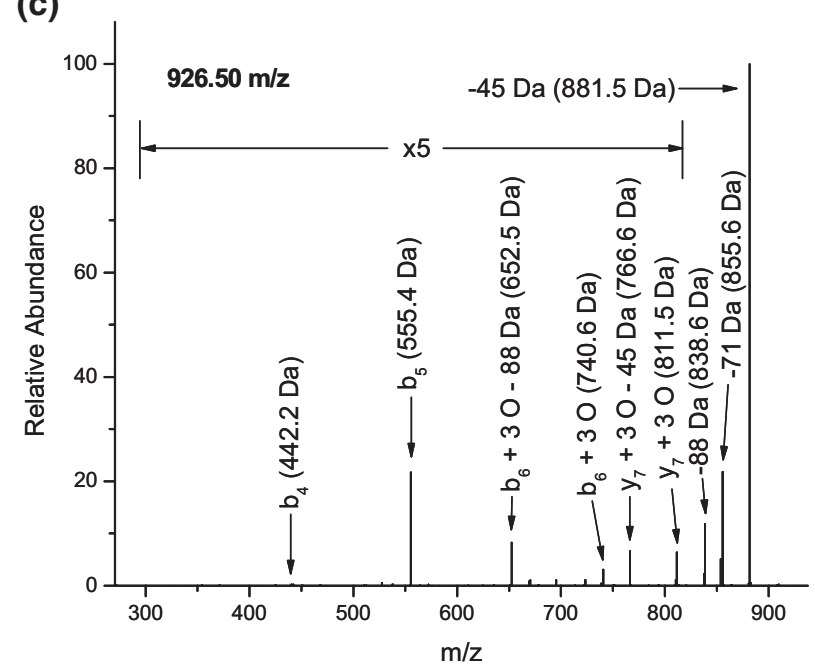

Figure 3. CID spectra of the $+3 \mathrm{O}$ adducts in (a) angiotensin II at $1094.5 \mathrm{~m} / \mathrm{z}$, (b) DRV $\underline{\text { IIAP }} \underline{\mathrm{A}}$ at $952.5 \mathrm{~m} / \mathrm{z}$, and (c) DRV $\underline{\mathrm{AI}} \underline{\mathrm{HP}} \underline{\mathrm{A}}$ at $926.5 \mathrm{~m} / \mathrm{z}$.

grouped according to adduction: $+\mathrm{O}$ (Figure 2), $+3 \mathrm{O}$ (Figure 3), and $+34 \mathrm{Da}$ (Figure 4). SID spectra for the $+\mathrm{O}$ and $+3 \mathrm{O}$ adducts of angiotensin II are shown in Figure 5. The SID spectra were obtained to confirm the

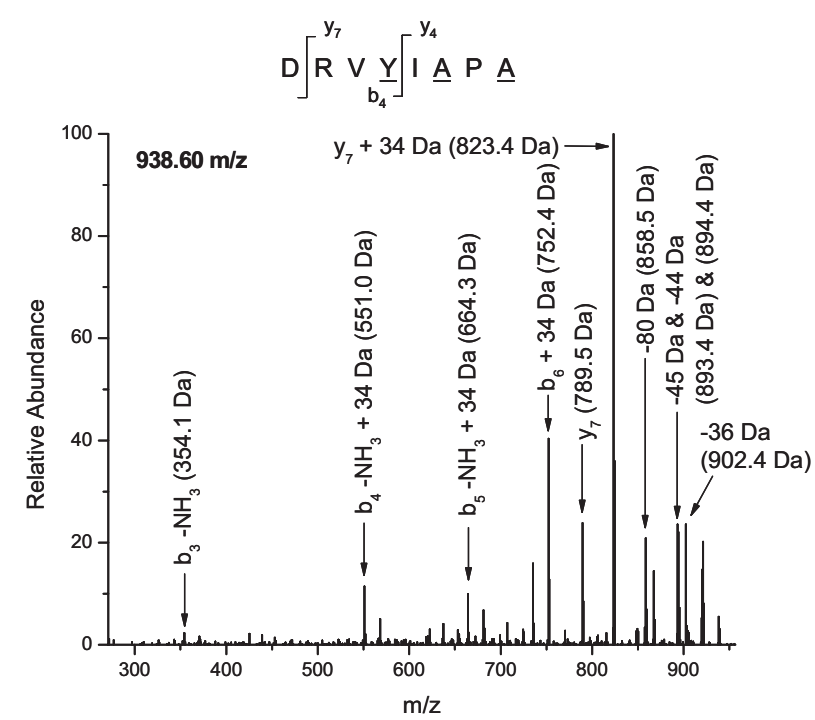

Figure 4. CID spectra of the +34 Da adduct in DRV $\underline{Y} \underline{I A P} \underline{A}$ at $938.5 \mathrm{~m} / \mathrm{z}$.

product ion assignments in the corresponding CID spectra. Table 2 summarizes the differences between measured and expected $\mathrm{m} / \mathrm{z}$ values for key ions observed in the SID spectra.

Figure 2a shows the CID spectrum of the $1062.5 \mathrm{~m} / \mathrm{z}$ ion of angiotensin II, which is expected to arise from the addition of one oxygen atom on the Tyr residue (Tyr + O). Since Tyr is located at the fourth residue in the sequence, the b-ion series is expected to shift by $16 \mathrm{Da}$ between $b_{4}$ and $b_{8}$ relative to the unmodified fragment ion. Similarly, a shift by $16 \mathrm{Da}$ is expected for y-ions between $\mathrm{y}_{5}$ and $\mathrm{y}_{8}$. All assignments shown in Figure 2a support formation of the Tyr $+\mathrm{O}$ adduct, which has been proposed to be 3,4- or 2,4-dihydroxyphenylalanine by Kotiaho et al. [27]. In contrast to CID, the SID spectrum showed more internal fragments and fewer sequence ions. Nonetheless, all Tyr-containing ions were observed at $\mathrm{m} / \mathrm{z}$ values shifted by $+16 \mathrm{Da}$ consistent with formation of the Tyr $+\mathrm{O}$ adduct (Table 2). Immonium ions of $\operatorname{Arg}(\mathrm{R})$ and $\mathrm{His}(\mathrm{H})$ were also detected using SID. Although all fragments from the SID spectrum of $1062.5 \mathrm{~m} / \mathrm{z}$ were consistent with formation of Tyr $+\mathrm{O}$, the $\mathrm{b}_{7}$ and $\mathrm{b}_{7}+\mathrm{H}_{2} \mathrm{O}$ ions in the CID spectrum do not correspond to this adduct. Compared to their oxygenated counterparts, these ions have much smaller intensities and are very close to the noise level. The presence of $b_{7}$ and $b_{7}+\mathrm{H}_{2} \mathrm{O}$ ions suggest a minor pathway in which an oxygen atom is added to the Phe residue. As mentioned previously, trace amounts of Phe $+\mathrm{O}$ and Phe $+2 \mathrm{O}$ may be formed during ozonolysis and detected by mass spectrometry [27]. Oxidation of the Phe residue could also occur by reaction with hydroxyl radicals under the conditions used.

Figure $2 \mathrm{~b}$ shows the CID spectrum of $920.5 \mathrm{~m} / \mathrm{z}$, the one oxygen adduct of A6, A8-angiotensin II, DRVYIAPA. The spectrum is very similar to that of the one oxygen adduct of angiotensin II $(1062.5 \mathrm{~m} / \mathrm{z})$ con- 
(a)

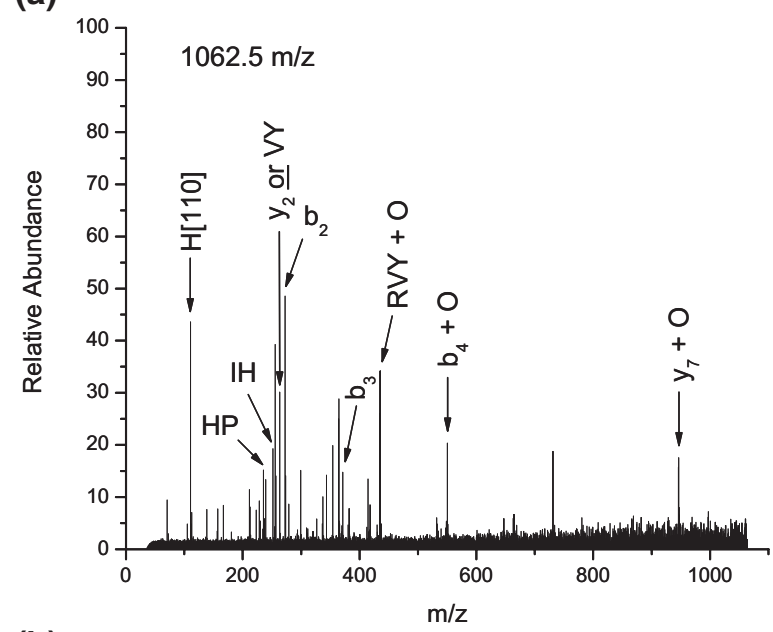

(b)

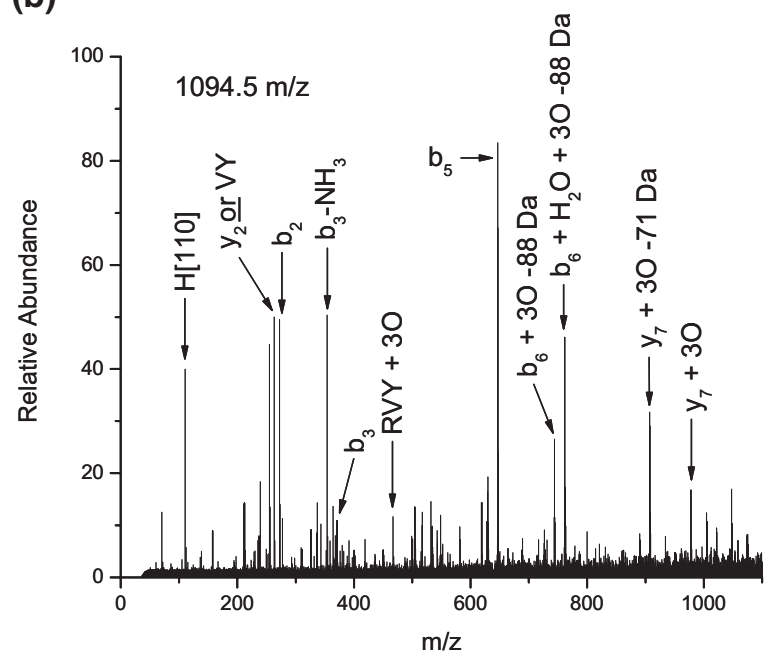

Figure 5. SID spectra of the $+\mathrm{O}(\mathbf{a})$ and $+3 \mathrm{O}(\mathbf{b})$ adducts of angiotensin II at 1062.5 and $1094.5 \mathrm{~m} / \mathrm{z}$ respectively. firming formation of Tyr $+\mathrm{O}$. All assigned ions are consistent with formation of the Tyr $+\mathrm{O}$ product. An ion at $414.2 \mathrm{~m} / \mathrm{z}$ and ions corresponding to the loss of both 138 and 110 Da from the precursor ion have not been conclusively assigned; however, these ions only appear in both CID spectra of the one oxygen adduct. One difference between Figure 2a and $b$ is the absence of nonoxygenated $b$-ions in the latter, which were assigned to the formation of Phe $+\mathrm{O}$ in the former. Since the analog did not contain phenylalanine, the absence of nonoxygenated b-ions in its spectrum further supports formation of the minor Phe + O product from angiotensin II.

The CID spectra of 1094.5, 926.5, and $952.5 \mathrm{~m} / \mathrm{z}$ show the $+3 \mathrm{O}$ adducts of angiotensin II, DRVYIAPA and DRVAIHPA, respectively (Figure 3a-c). Based on previous work, it was expected that only the His residue would gain three oxygen atoms during ozonolysis; however, the CID and SID data suggest otherwise (Figure $3 a$ and Table 2). Because His is the sixth residue from the $\mathrm{N}$-terminus, $\mathrm{b}_{6}$ to $\mathrm{b}_{8}$ and $\mathrm{y}_{3}$ to $\mathrm{y}_{8}$ are expected to be shifted by $+48 \mathrm{Da}$. In addition, His immonium ions and His-containing internal fragments are expected to be shifted by $+48 \mathrm{Da}$. While most fragment ions in the angiotensin II CID and SID spectra are consistent with the His $+3 \mathrm{O}$ adduct, some are not. The SID spectrum shows the His immonium ions at 110.07 and $138.07 \mathrm{~m} / \mathrm{z}$ and the internal fragment $\mathrm{HP}$ at 235.12 $\mathrm{m} / \mathrm{z}$, suggesting the presence of another $+3 \mathrm{O}$ adduct in which the His side-chain is not oxidized. Other unexpected sequence ions were detected in the CID spectrum corresponding to the $\mathrm{b}_{5}+3 \mathrm{O}$ and $\mathrm{m}_{4}+3 \mathrm{O}$ ions. The $\mathrm{m}$-ion series relates to the loss of the entire residue side chain. Therefore, in angiotensin II, $\mathrm{m}_{4}+3 \mathrm{O}$ shows the loss of the Tyr side chain plus three oxygen atoms.

Table 2. Fragment ions from SID spectra of each ozonolysis product of angiotensin II

\begin{tabular}{|c|c|c|c|c|}
\hline Precursor ion & b-lons & y-lons & Immonium ions & Internal fragments \\
\hline $\mathrm{MH}^{+} 1046.5423 \mathrm{Da}$ & $\begin{array}{l}\mathrm{b}_{2}(0.0004), \mathrm{b}_{3} \\
(-0.0008), \mathrm{b}_{4} \\
(-0.0014), \mathrm{b}_{6} \\
(-0.0029)\end{array}$ & $\begin{array}{c}\mathrm{y}_{2}{ }^{\mathrm{a}}(0.0002), \mathrm{y}_{4}{ }^{\mathrm{a}} \\
(-0.0003), \mathrm{y}_{7} \\
(-0.0033)\end{array}$ & $\begin{array}{l}\mathrm{R}[70]^{\mathrm{a}}(-0.0004), \\
\mathrm{P}^{\mathrm{a}}(-0.0004), \\
\mathrm{H}[110](-0.0003), \\
\mathrm{R}[112](-0.0004), \\
\mathrm{Y}(0.0005), \\
\mathrm{H}[138](-0.0001)\end{array}$ & $\begin{array}{l}\text { HP }(-0.0004), \text { IH }(-0.0001), \\
\text { RV }(0.0004), \text { VYa }(0.0002), \\
\text { VYI (0.0019), YIH } \\
(0.0005), \text { RVY }(-0.0016), \\
\text { VYIH }(-0.0003), \text { RVYI } \\
(-0.0014), \text { RVYIH } \\
(0.0038)\end{array}$ \\
\hline $\begin{array}{l}(\mathrm{M}+\mathrm{O})+\mathrm{H}^{+} \\
1062.5372 \mathrm{Da}\end{array}$ & $\begin{array}{l}\mathrm{b}_{2}(0.0001), \mathrm{b}_{3} \\
\quad(-0.0016), \mathrm{b}_{4}+ \\
\mathrm{O}(-0.0015)\end{array}$ & $\begin{array}{l}\mathrm{y}_{2}^{\mathrm{a}}(-0.0005), \mathrm{y}_{2}+ \\
\mathrm{O}^{\mathrm{a}}(-0.0003), \mathrm{y}_{7}+ \\
\mathrm{O}(0.013)\end{array}$ & $\begin{array}{l}R[70]^{\mathrm{a}}(-0.0003), \\
\quad \mathrm{P}^{\mathrm{a}}(-0.0003), \\
\mathrm{H}[110](-0.0001), \\
\mathrm{R}[112](-0.0002), \\
\mathrm{H}[138](0.0002)\end{array}$ & $\begin{array}{l}\mathrm{HP}(-0.0006), \mathrm{IH}(-0.0008), \\
\mathrm{RV}(-0.0005), \mathrm{VY}{ }^{\mathrm{a}} \\
(-0.0005), \mathrm{VY}+\mathrm{O} \\
(-0.0003), \mathrm{RVY}+\mathrm{O} \\
(-0.0037)\end{array}$ \\
\hline $\begin{array}{r}(\mathrm{M}+3 \mathrm{O})+\mathrm{H}^{+} \\
1094.5271 \mathrm{Da}\end{array}$ & $\begin{array}{l}\mathrm{b}_{2}(0.0005), \mathrm{b}_{3} \\
(0.0009), \mathrm{b}_{5} \\
(-0.0004), \mathrm{b}_{6}+ \\
30-88 \mathrm{Da} \\
(-0.0029), \mathrm{b}_{6}+ \\
\mathrm{H}_{2}+30-88 \mathrm{Da} \\
(0.0009)\end{array}$ & $\begin{array}{c}\mathrm{y}_{2}^{\mathrm{a}}(0.0004), \mathrm{y}_{7}+30 \\
(-0.0025), \mathrm{y}_{7}+ \\
30-71 \mathrm{Da}(0.0033)\end{array}$ & $\begin{array}{l}R[70]^{a}(-0.0001), \\
P^{a}(-0.001), \\
H[110](0.00002), \\
R[112](0.00003), \\
H[138](0.0003)\end{array}$ & $\begin{array}{l}\mathrm{HP}(-0.0002), \mathrm{RV}(0.0003) \\
\text { VYa }(0.0004), \mathrm{YI}(0.0014) \\
\mathrm{UHP}+30-28 \mathrm{Da} \\
(-0.0016), \mathrm{VYI}(0.0009) \\
\text { RVY }(0.0007), \mathrm{RVY}+30 \\
(0.0015), \mathrm{RVYI}(0.0018)\end{array}$ \\
\hline
\end{tabular}

\footnotetext{
a Ions have the same $\mathrm{m} / \mathrm{z}$ within experimental error as other fragmentation products. The difference between measured and expected $\mathrm{m} / \mathrm{z}$ values are
} shown in parenthesis. 


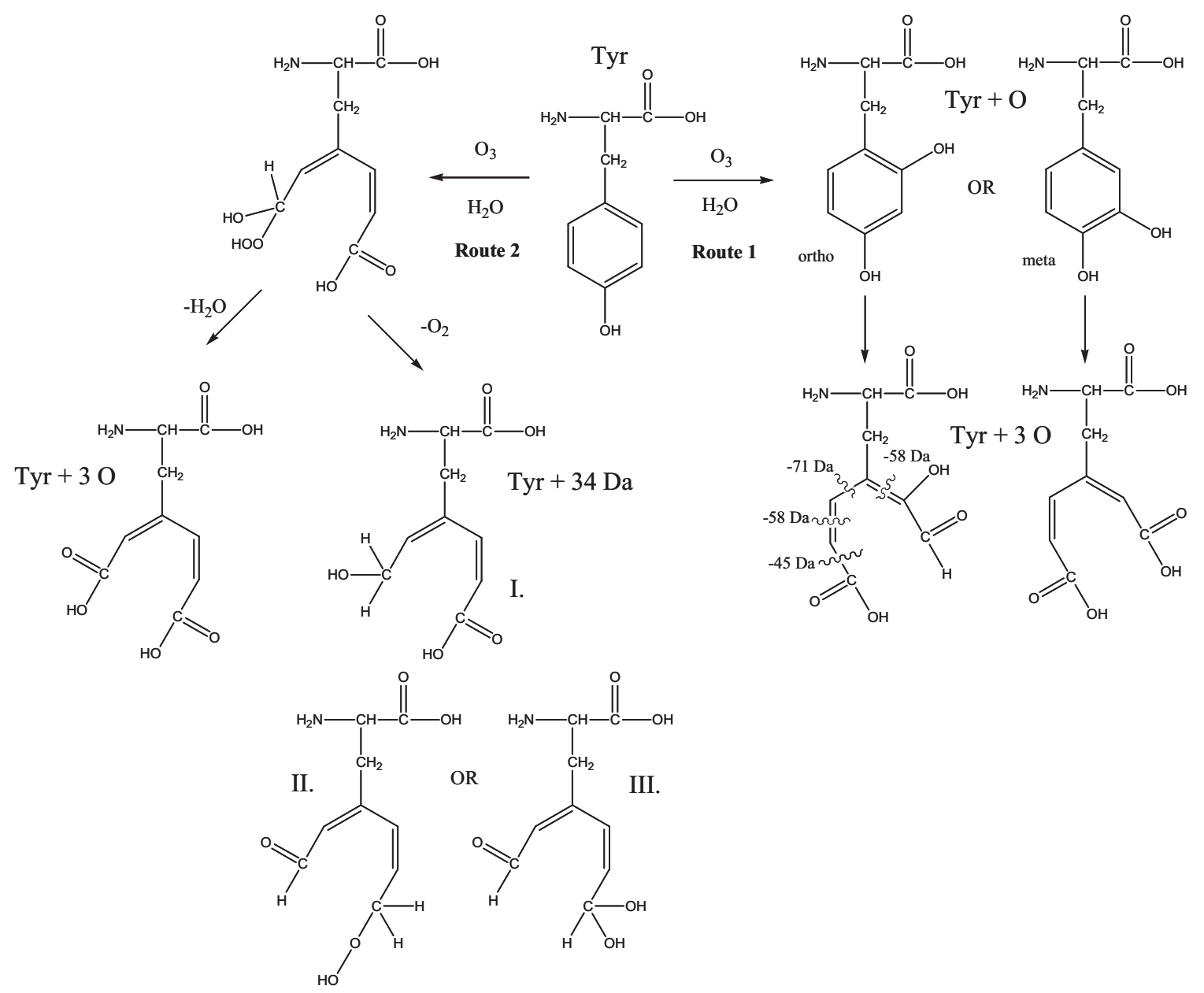

Scheme 1. Proposed product structures of tyrosine ozonolysis. Route 1 shows the first step to be hydroxylation on the ring, and route 2 shows the first step to be bond cleavage of the ring.

These ions are strong indicators that three oxygen atoms can also be added to the Tyr residue.

To investigate this possible product $(\mathrm{Tyr}+3 \mathrm{O})$, the CID spectra of the $+3 \mathrm{O}$ adducts of the Tyr analog (DRVYIAPA) at $952.5 \mathrm{~m} / z$ and angiotensin II at 1094.5 $\mathrm{m} / \mathrm{z}$ were compared. In the CID spectrum of $952.5 \mathrm{~m} / \mathrm{z}$ (Figure $3 b$ ), a mass shift of +48 Da is observed for $b_{4}-b_{7}$ ions and the $\mathrm{y}_{7}$ ion as expected for oxidation of the Tyr residue. Interestingly, an abundant peak at $513.3 \mathrm{~m} / \mathrm{z}$ appears to correspond to the loss of the oxygenated Tyr side chain from the $a_{5}$ ion. Again, the $m_{4}+30$ ion is present as well as losses of $44 \mathrm{Da}\left(\mathrm{CO}_{2}\right)$ and $58 \mathrm{Da}$ $(-\mathrm{CHCOOH})$ from the molecular ion, which were also found in the CID spectrum of angiotensin II. The neutral losses suggest that the Tyr $+3 \mathrm{O}$ adduct is a ring-opened degradation product as shown in Scheme 1. The neutral loss of $71 \mathrm{Da}$ from the molecular ion $(-\mathrm{CHCHCOOH})$ is likely to result from the Tyr $+3 \mathrm{O}$ product structures as well; however, it shares the same $m / z$ value as the $\mathrm{b}_{7}+\mathrm{H}_{2} \mathrm{O}+3 \mathrm{O}$ ion.

The proposed product structures for the ozonolysis of Tyr are based on previous ozone studies of phenols [38-40] (Scheme 1). Niki and coworkers [38] proposed two possible initial routes of ozonolysis: hydroxylation or bond cleavage. In the hydroxylation route, intermediates are formed that correspond to the addition of one and three oxygen atoms. Different product structures can be formed depending on whether the ozone initially attacks the phenol/tyrosine side chain ortho or meta in relation to the hydroxyl group. Initial bond cleavage of the ring also leads to the addition of three oxygen atoms (Tyr + $3 \mathrm{O})$ as well as the $+34 \mathrm{Da}$ adduct, which was observed in low abundance in the ESI-MS of DRV $\underline{Y} \underline{A P} \underline{A}$. Recently, a study by Dai et al. [41] observed the +34 and +48 Da products following oxidation of peptides using performic acid. In their work, the mass shift of +34 Da on the Tyr residue was attributed to the addition of chlorine. However, it was noted that no chloride-containing reagents were specifically added to the experiment.

Like the experiment reported by Dai et al. [41], no chlorine was added in our experiments and further characterization of the $+34 \mathrm{Da}$ adduct in DRV $\underline{Y} \underline{I A P} \underline{A}$ was conducted by CID (Figure 4). A mass shift of +34 Da observed for $b_{4}-b_{7}$ and $y_{7}$ ions as well as the unmodified $b_{3}$ ion suggest that this adduct corresponds to the oxidation on Tyr. The intense peak at 


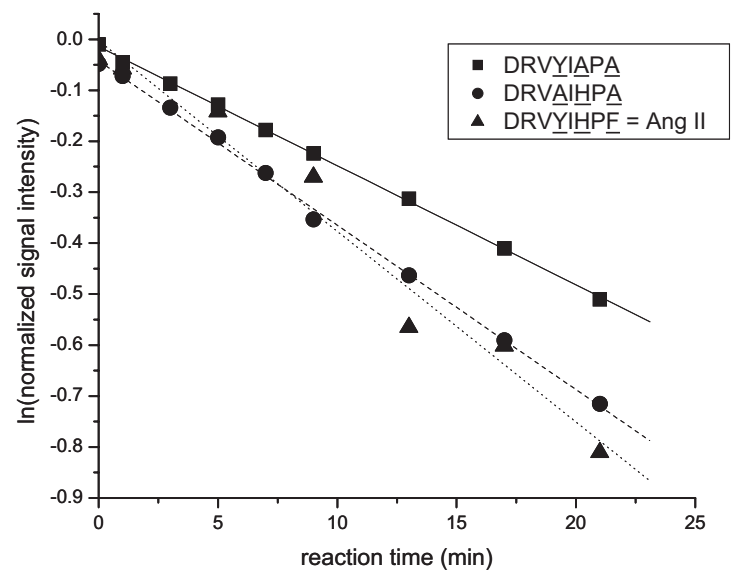

Figure 6. Plot of the logarithm of normalized signal intensity versus reaction time for angiotensin II and two analogs. The decreased signal intensity correlates to the relative reactivity of Tyr and His.

$789.5 \mathrm{~m} / \mathrm{z}$ corresponds to an unmodified $\mathrm{y}_{7}$ fragment ion. Possibly, the $\mathrm{y}_{7}$ ion is formed by consecutive fragmentation of the $y_{7}+34$ ion. Two of the proposed +34 Da adduct structures (Scheme 1), the aldehyde/ peroxide (II), and the aldehyde/diol (III) can easily fragment by loss of $\mathrm{H}_{2} \mathrm{O}_{2}(34 \mathrm{Da})$. High $\mathrm{m} / \mathrm{z}$ ions corresponding to losses of $44 \mathrm{Da}\left(\mathrm{CO}_{2}\right)$ and $45 \mathrm{Da}$ $(-\mathrm{COOH})$ could occur from the acid/alcohol (I) also shown in Scheme 1. The loss of $\mathrm{CO}_{2}$ occurs only after a hydrogen rearrangement. The loss of 80 Da corresponds to the loss of two water molecules (36 Da) and $\mathrm{CO}_{2}(44 \mathrm{Da})$, which could occur from any of the +34 Da adducts. The two water molecules could be lost where one molecule leaves from the C-terminus and the other from the ring-opened product.

Figure $3 c$ shows the CID spectrum of $926.5 \mathrm{~m} / \mathrm{z}$, the $+3 \mathrm{O}$ adduct of DRV $\underline{\mathrm{AI}} \underline{\mathrm{HP}} \underline{\mathrm{A}}$. The observed fragmentation confirms formation of $\mathrm{His}+3 \mathrm{O}$ and suggests a structure of 2-amino-4-oxo-4-(3-formylureido)butanoic acid as proposed by Kotiaho et al. [27]. Sequence ions with a mass shift of $+48 \mathrm{Da}$ include $\mathrm{b}_{6}+$ $3 \mathrm{O}, \mathrm{y}_{7}+3 \mathrm{O}, \mathrm{b}_{6}+3 \mathrm{O}-88 \mathrm{Da}$, and $\mathrm{y}_{7}+3 \mathrm{O}-45 \mathrm{Da}$. Sequence ions that do not shift include $b_{4}$ and $b_{5}$ as expected for the His $+3 \mathrm{O}$ adduct. Important high $\mathrm{m} / \mathrm{z}$ ions correspond to the loss of $45 \mathrm{Da}\left(\mathrm{NH}_{2} \mathrm{COH}\right), 71$ $\mathrm{Da}$ (CO and HNCO), and $88 \mathrm{Da}$ (NHCO and $\mathrm{NH}_{2} \mathrm{COH}$ ) from the oxidized His side chain. These neutral losses are also observed in the CID spectrum of angiotensin II (Figure 3a). In contrast, the loss of 58 Da observed for the $+3 \mathrm{O}$ adduct of angiotensin II is not found in DRV $\underline{A} \underline{H P} \underline{A}$, which further confirms that the ozonolysis of angiotensin II can produce both Tyr $+3 \mathrm{O}$ and $\mathrm{His}+3 \mathrm{O}$ adducts.

\section{Reaction Kinetics}

Figure 6 shows plots for all three compounds of the logarithm of normalized peptide signal intensity (peptide, i.e., reactant, ion signal divided by the sum of reactant and product ion signals) versus reaction time with ozone for angiotensin II and its two analogs. The decrease of the reactant ion signal intensity correlates to the ozone reactivity of an isolated Tyr residue in DRV $\underline{\text { IAPPA }}$ and an isolated His residue is

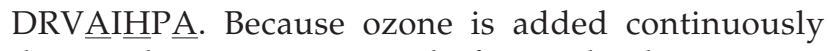
during the reaction, pseudo-first-order kinetics are followed (eq 1). The slopes of the lines in Figure 6 give values for $\mathrm{k}$, the pseudo-first-order rate constant. The second-order rate coefficients, $\mathrm{k}_{\mathrm{II}}$, are calculated based on the concentration of ozone derived from Henry's Law (Table 3):

$$
\ln (\text { normalized signal intensity })=-k t=-k_{I I}\left[O_{3}\right] t
$$

The use of eq 1 to determine reaction rates requires (1) that the signal intensity is not subjected to quenching by the presence of reaction products, and (2) that the relative sensitivities for detection of the Tyr and His products are the same. The first assumption was verified by standard addition. Analysis of standard peptide solutions at concentrations ranging from 0.0015 to $0.75 \mathrm{mg} / \mathrm{mL}$ showed a linear relationship between averaged signal intensity and concentration with an R2 value of 0.998. Adding known amounts of the unreacted peptide to solutions after ozone reaction showed no change in calibration sensitivity, i.e., the slope of the plot of signal intensity versus concentration, in the presence of oxidized product. In addition, the lack of deviation from the linear fits in Figure 6 suggests similar detection sensitivities for reactants and products.

The rate coefficients in Table 3 show the ozone reactivity of an isolated His residue to be only slightly greater than that of an isolated Tyr residue, which is consistent with previous work based on model peptides [27] and proteins [16]. Angiotensin II contains both His and Tyr residues and hence shows the greatest reactivity toward ozone. However, the reactivities of the individual residues are not additive: the rate coefficient for angiotensin II is smaller than the sum of the rate coefficients of the other two peptides. Non-additivity could arise from the local competition for ozone between Tyr and His in angiotensin II or a slight change of secondary structure caused by the replacement of Phe, Tyr and/or His with Ala. For peptides, the effect is minor as the sum of the rate coefficients for the isolated residues differs from the angiotensin II rate coefficient by less than $50 \%$.

Table 3. Experimentally determined pseudo-first order rate coefficient, $\mathrm{k}$, and the second-order rate coefficient, $\mathrm{k}_{\mathrm{II}}$, for the reaction of ozone with angiotensin II and its analogs.

\begin{tabular}{lcc}
\hline \multicolumn{1}{c}{ Peptide } & $\mathrm{k} \times 10^{-4}\left(\mathrm{~s}^{-1}\right)^{\mathrm{a}}$ & $\mathrm{k}_{\mathrm{ll}}\left(\mathrm{M}^{-1} \mathrm{~s}^{-1}\right)^{\mathrm{a}}$ \\
\hline \hline DRVYIAPA & $3.90 \pm 0.04$ & $274 \pm 3$ \\
DRVAIIHPA & $5.38 \pm 0.08$ & $379 \pm 6$ \\
DRV $\underline{\text { I }}$ 표 $\underline{\mathrm{F}}=$ Ang II & $6.2 \pm 0.5$ & $439 \pm 34$ \\
\hline
\end{tabular}

aUncertainities are given to one standard deviation. 
Reaction rates have been measured in other studies for residues within proteins [16] and for free amino acids [23]. Unfortunately, the rate coefficients for His and Tyr residues in larger proteins determined by Berlett et al. [16] are not directly comparable to our work owing to a lack of information on the reactant concentrations. Pryor et al. [23] report second-order rate coefficients for the free amino acid histidine, ranging from $38 \mathrm{M}-1 \mathrm{~s}-1$ at $\mathrm{pH} 2$ to $2.0 \times 105$ M-1s-1 at $\mathrm{pH} 7$. The rate coefficient for the free amino acid at a pH 3.5 is approximately equal to that of the His residue in DRV $\underline{\mathrm{AI}} \underline{\mathrm{HP}} \underline{\mathrm{A}}$ in an unbuffered solution.

\section{Conclusions}

MS and MSMS studies of ozonated angiotensin II and its analogs show that Tyr $+3 \mathrm{O}$ and Tyr $+34 \mathrm{Da}$ adducts can be formed in addition to $\mathrm{His}+3 \mathrm{O}$, Tyr + $\mathrm{O}$, and Phe $+\mathrm{O}$ adducts, which have been previously observed in amino acid ozonolysis. Tandem mass spectra were used to identify the structures of the newly observed adducts as well as those suggested from previous work. Other minor oxidation products were observed during ozonolysis including $\mathrm{His}+5$ $\mathrm{Da}$, His $+34 \mathrm{Da}$, and His $+82 \mathrm{Da}$. Each of these adducts can be rationalized through the continued oxidation of the oxidized products and/or nonspecific targets on the peptide.

Second-order rate coefficients were determined from the decrease of the normalized signal intensity versus time. The rate coefficients show that an isolated His residue reacts slightly faster than an isolated Tyr residue, and angiotensin II (which contains both residues) reacts faster than peptides containing only one of the two residues. However, the angiotensin II rate coefficient does not equal the sum of the rate coefficients from His and Tyr.

The ozone concentration used in these experiments was 1000 times greater than is typically found in ambient air. The use of such a large concentration facilitated measurement of reaction rates and calculation of $\mathrm{k}_{\mathrm{II}}$ values. If the reaction rates scale linearly with ozone concentration and no other decomposition pathways are available, then the atmospheric lifetimes of these peptides are expected to be about 20-30 days.

\section{Acknowledgments}

This research was supported by NSF grants CHE-0098831 and CHE-0517972. Surface-induced dissociation experiments were performed at the W. R. Wiley Environmental Molecular Sciences Laboratory, a national scientific user facility sponsored by the U.S. Department of Energy's Office of Biological and Environmental Research and located at Pacific Northwest National Laboratory (PNNL). PNNL is operated by Battelle for the U.S. Department of Energy. Research at EMSL was supported by a grant from the Chemical Sciences Division, Office of Basic Energy Sciences of the U.S. Department of Energy. JMS acknowledges participation in the PNNL Interfacial and Con- densed Phase Summer Research Institute and fellowship support through NSF-IGERT grant DGE-0221651.

\section{References}

1. Ross, M. A.; Persky, V. W.; Scheff, P. A.; Chung, J.; Curtis, L.; Ramakrishnan, V.; Wadden, R. A.; Hryhorczuk, D. O. Effect of Ozone and Aeroallergens on the Respiratory Health of Asthmatics. Arch. Environ. Health 2002, 57, 568-578.

2. Weisel, C. P.; Codt, R. P.; Lioy, P. J. Relationship Between Summertime Ambient Ozone Levels and Emergency Department Visits for Asthma in Central New Jersey. Environ. Health Perspect. 1995, 103, 97-102.

3. Schmut, O.; Gruber, E.; El-Shabrawi, Y.; Faulborn, J., Destruction of Human Tear Proteins by Ozone.Free Rad. Biol. Med. 1994, 17, 165-169.

4. Menzel, D. B. Ozone: An Overview of its Toxicity in Man and Animals. J. Toxicol. Environ. Health 1984, 13, 183-204.

5. Ashmore, M. R.; Marshall, F. M. Ozone Impacts on Agriculture: An Issue of Global Concern. Adv. Botan. Res. 1999, 29, 31-52.

6. Dell'era, R.; Brambilla, E.; Ballarin-Denti, A. Ozone and Particulate Measurements in Mountain Forest Sites. Chemosphere 1998, 36, 10831088.

7. Uppu, R. M.; Pryor, W. A. The Reactions of Ozone with Proteins and Unsaturated Fatty Acids in Reverse Micelles. Chem. Res. Toxicol. 1994, 7, 47-55.

8. Uppu, R. M.; Cueto, R.; Squadrito, G. L.; Pryor, W. A. What Does Ozone React with at the Air/Lung Interface? Model Studies Using Human Red Blood Cell Membranes. Arch. Biochem. Biophys. 1995, 319, 257-266.

9. Pryor, W. A.; Uppu, R. M. A Kinetic Model for the Competitive Reactions of Ozone with Amino Acid Residues in Proteins in Reverse Micelles. J. Biol. Chem. 1993, 268, 3120-3126.

10. Mudd, J. B.; Dawson, P. J.; Tseng, S.; Liu, F. Reaction of Ozone with Protein Tryptophans: Band III, Serum Albumin, and Cytochrome $c$. Arch. Biochem. Biophys. 1997, 338, 143-149.

11. Cataldo, F. On the Action of Ozone on Proteins. Polym. Degrad. Stab. 2003, 82, 105-114.

12. O'Neill, C. A.; van der Vliet, A.; Hu, M.; Kaur, H.; Cross, C. E.; Louie, S.; Halliwell, B. Oxidation of Biologic Molecules by Ozone: The Effect of pH. J. Lab. Clin. Med. 1993, 122, 497-505.

13. Kanofsky, J. R.; Sima, P. D. Singlet Oxygen Production from the Reactions of Ozone with Biological Molecules. J. Biol. Chem. 1991, 266, 9039-9042.

14. Kuroda, M.; Sakiyama, F.; Narita, K. Oxidation of Tryptophan in Lysozyme by Ozone in Aqueous Solution. J. Biochem. 1975, 78, 641-651.

15. Dooley, M. M.; Mudd, J. B. Reaction of Ozone with Lysozyme Under Different Exposure Conditions. Arch. Biochem. Biophys. 1982, 218, 459471 .

16. Berlett, B. S.; Levine, R. L.; Stadtman, E. R. Comparison of the Effects of Ozone on the Modification of Amino Acid Residues in Glutamine Synthetase and Bovine Serum Albumin. J. Biol. Chem. 1996, 271, 41774182

17. Knight, K. L.; Mudd, J. B. The Reaction of Ozone with Glyceraldehyde3-Phosphate Dehydrogenase. Arch. Biochem. Biophys. 1984, 229, 259-269.

18. Mudd, J. B.; Dawson, P. J.; Adams, J. R.; Wingo, J.; Santrock, J. Reaction of Ozone with Enzymes of Erythrocyte Membranes. Arch. Biochem. Biophys. 1996, 335, 145-151.

19. Boreson, J.; Dillner, A. M.; Peccia, J. Correlating Bioaerosol Load with PM 2.5 and PM 10 cf Concentrations: A Comparison Between Natural Desert and Urban-Fringe Aerosols. Atmos. Environ. 2004, 38, 6029-6041.

20. Mikhailov, E.; Vlasenko, S.; Niessner, R.; Poschl, U. Interaction of Aerosol Particles Composed of Protein and Salts with Water Vapor: Hygroscopic Growth and Microstructural Rearrangement. Atmos. Chem. Phys. 2004, 4, 323-350.

21. Hazra, A.; Saha, M.; De, U. K.; Mukherjee, J.; Goswami, K. Study of Ice Nucleating Characteristics of Pseudomonas aeruginosa. J. Aerosol. Sci. 2004, 35, 1405-1414.

22. Miguel, A. G.; Cass, G. R.; Glovsky, M. M.; Weiss, J. Allergens in Paved Road Dust and Airborne Particles. Environ. Sci. Technol. 1999, 33, 4159-4168

23. Pryor, W. A.; Giamalva, D. H.; Church, D. F. Kinetics of Ozonation. 2. Amino Acids and Model Compounds in Water and Comparisons to Rates in Nonpolar Solvents. J. Am. Chem. Soc. 1984, 106, 7094-7100.

24. Mudd, J. B.; Leavitt, R.; Ongun, A.; McManus, T. T. Reaction of Ozone with Amino Acids and Proteins. Atmos. Environ. 1969, 3, 669-682.

25. Previero, A.; Scoffone, E.; Pajetta, P.; Benassi, C. A. The Structure of Proteins: X. The Behavior of Amino Acids in the Presence of Ozone.Gazz. Chim. Ital. 1963, 93, 841-848.

26. Previero, A.; Scoffone, E.; Benassi, C. A.; Pajetta, P. Investigations on the Structure of Proteins: XI. Modification of the Tryptophan Residue in a Peptide Chain. Gazz. Chim. Ital. 1963, 93, 849-858.

27. Kotiaho, T.; Eberlin, M. N.; Vainiotalo, P.; Kostiainen, R. Electrospray Mass and Tandem Mass Spectrometry Identification of Ozone Oxidation Products of Amino Acids and Small Peptides. J. Am. Soc. Mass Spectrom. 2000, 11, 526-535.

28. Finlayson-Pitts, B. J.; Pitts, J. N. J. Chemistry of the Upper and Lower Atmosphere; Academic Press: New York, 1999. p 152.

29. Laskin, J.; Denisov, E. V.; Shukla, A. K.; Barlow, S. E.; Futrell, J. H. Surface-Induced Dissociation in a Fourier Transform Ion Cyclotron 
Resonance Mass Spectrometer: Instrument Design and Evaluation. Anal. Chem. 2002, 74, 3255-3261.

30. Maleknia, S. D.; Chance, M. R.; Downard, K. M. Electrospray-Assisted Modification of Proteins: A Radical Probe of Protein Structure. Rapid Commun. Mass Spectrom. 1999, 13, 2352-2358.

31. Morand, K.; Talbo, G.; Mann, M. Oxidation of Peptides During Electrospray Ionization. Rapid Commun. Mass Spectrom. 1993, 7, 738-743.

32. Sharp, J. S. Becker, J. M. Hettich, R. L. Analysis of Protein Solven Accessible Surfaces by Photochemical Oxidation and Mass Spectrometry. Anal. Chem. 2004, 76, 672-683.

33. Hoigne, J.; Bader, H. Ozonation of Water: Role of Hydroxyl Radicals a Oxidizing Intermediates. Science 1975, 190, 782-784.

34. Kanofsky, J. R.; Sima, P. D. Singlet-Oxygen Generation at Gas-Liquid Interfaces: A Significant Artifact in the Measurement of Singlet-Oxygen Yields from Ozone-Biomolecule Reactions. Photochem. Photobiol. 1993, $58,335-340$.

35. Xu, G.; Takamoto, K.; Chance, M. R. Radiolytic Modification of Basic Amino Acid Residues in Peptides: Probes for Examining ProteinProtein Interactions. Anal. Chem. 2003, 75, 6995-7007.
36. Uchida, K.; Kawakishi, S. Reaction of a Histidyl Residue Analogue with Hydrogen Peroxide in the Presence of Copper(II) Ion. J. Agric. Food Chem. 1990, 38, 660-664.

37. Uchida, K.; Kawakishi, S. Ascorbate-Mediated Specific Oxidation of the Imidazole Ring in a Histidine Derivative. Bioorg. Chem. 1989, 17, 330-343.

38. Yamamoto, Y.; Niki, E.; Shiokawa, H.; Kamiya, Y. Ozonation of Organic Compounds. 2. Ozonation of Phenol in Water. J. Org. Chem. 1979, 44, 2137-2142.

39. Eisenhauer, H. R. Dephenolization by Ozonolysis. Water Res. 1971, 5, 467-472.

40. Eisenhauer, H. R. Ozonization of phenolic wastes. J.-Water Pollut. Control Fed. 1968, 40, 1887-1899.

41. Dai, J.; Zhang, Y.; Wang, J.; Li, X.; Lu, Z.; Cai, Y.; Qian, X. Identification of Degradation Products Formed During Performic Oxidation of Peptides and Proteins by High-Performance Liquid Chromatography with Matrix-Assisted Laser Desorption/Ionization and Tandem Mass Spectrometry. Rapid Commun. Mass Spectrom. 2005, 19, 1130-1138. 